\title{
Crop selection under price and yield fluctuation: Analysis of agro-economic time series from South Korea
}

\author{
Heera Lee ${ }^{\mathrm{a}, \mathrm{b}, *}$, Christina Bogner ${ }^{\mathrm{c}}$, Saem Lee ${ }^{\mathrm{a}}$, Thomas Koellner ${ }^{\mathrm{a}}$ \\ ${ }^{a}$ Professorship of Ecological Services, Faculty of Biology, Chemistry and Earth Sciences, BayCEER, \\ University of Bayreuth, Universitaetsstrasse 30, 95440 Bayreuth, Germany \\ ${ }^{b}$ Faculty of Agriculture, Land use Modelling and Ecosystem Services, University of Bonn, Nussallee 1, \\ 53115 Bonn, Germany \\ ${ }^{c}$ Ecological Modelling, BayCEER, University of Bayreuth, Dr.-Hans-Frisch-Strasse 1-3, 95448 Bayreuth, \\ Germany
}

\begin{abstract}
Temporal fluctuations of crop price and yield can have a strong influence on farmers' revenue. Under uncertainty, farmers' crop selection on - what to cultivate and how much of their land to allocate to different crops- is of crucial importance to secure their revenue as well as related ecosystem services. Multi-crop farming can be seen as a strategy to mitigate uncertainties that farmers face. In this study, we used Singular Spectrum Analysis (SSA) to quantify the fluctuations of crop price and yield for single and multiple crop selections in South Korea. Furthermore, risk adjusted revenue of each crop selection was analysed using the Sharpe ratio. We constructed three empirical crop portfolios containing one, three and five crops. For the single crop farming, six main crops in South Korea were analysed, and household data were used to build empirical crop portfolios. Our results showed that revenue from rice farming was the most stable, whereas it fluctuated strongly for pepper. However, growing rice provided the lowest revenue and farmers who cultivate multiple crops might as much as double their revenue compared to rice farming. Diversified crop farming can be a means of enhancing revenue. The biggest part of fluctuations in portfolios with several crops was seasonal, which might be mitigated by planning in advance. The artificial stability of rice price was due to policy intervention. However, it should be noted that the rice policy has been reformed and a high protection for domestic rice farming would no longer last in the future in South Korea. These results might have practical consequences for farmers' decision making on crop selection as well as for agricultural policy.
\end{abstract}

Keywords: Crop choice, Crop portfolio, Time series analysis, Fluctuation analysis, Singular Spectrum Analysis (SSA)

\section{Introduction}

Farmers face various types of risks in agricultural production including price fluctuations that can be caused by the dynamics of global economics or climate change (e.g. Janssen and

*Corresponding author: Tel.: +49 228 732925; Fax: +49 228733708

Email address: hlee@uni-bonn.de (Heera Lee)

This is an author's post-print version of the article published in Agricultural Systems, 148, 1-11 (2016) doi:10.1016/j.agsy.2016.06.003. 
van Ittersum, 2007; Fader et al., 2013; Feola et al., 2015). The tendency of the world prices for agricultural commodities to fluctuate over time makes farmers more vulnerable (FAO et al., 2011). These fluctuations, particularly if large and unexpected, can threaten the stability of the farm household income (FAO et al., 2011) - one of the key indicators to farm well-being (Mishra et al., 2002). Unexpected price volatility and changing environmental conditions can make it harder for farmers to decide what to cultivate and when to harvest it. However, these decisions are of crucial importance to secure their revenue and are tightly related to food security ${ }^{1}$.

Accordingly, substantial efforts are being directed towards reducing risks and ensuring revenue stability on the farm household level (Bradshaw et al., 2004; Harvey et al., 2014; Wood et al., 2014; Feola et al., 2015). Farmers tend to change the type of crops (Wang et al., 2010; Klasen et al., 2013), land management practices (Wood et al., 2014), and the growing season (Olesen et al., 2011), or extend the scope of income by including off-farm income (Bradshaw, 2004; Harvey et al., 2014), for example. Several studies pointed out that decisions on such practices were influenced by socio-economic background of farmers such as age (Potter and Lobley, 1992; van Dusen and Taylor, 2005), education (Below et al., 2012) and income (Awan et al., 2015). As farmers are the main actors who promote agricultural adaptation and contribute to food security (Kristensen et al., 2001; Feola et al., 2015), it is important to take account of their socio-economic background in relation to their behaviour. This information could help to understand why some take a certain action to adapt to changes and others omit it (Ilbery, 1978; Cutforth et al., 2001; Fader et al., 2013; Herrero et al., 2014; Feola et al., 2015).

One of the critical decisions that farmers face is crop selection - what to cultivate and how much of their land to allocate to different crops (Rădulescu et al., 2014). As each crop has different trends of price and yield, farmers can reduce risk by cultivating more than one crop. Crop diversity can thus be considered as one of the strategies to mitigate the risk and the uncertainties that farmers face (Heady, 1952; Bhattacharyya, 2008; Rahman, 2009; Pellegrini and Tasciotti, 2014) through the portfolio effect. The portfolio theory (Markowitz, 1952) states that the investor can minimise the risk under uncertainty and stabilise the return by investing in more than one asset. It has been applied in various fields of ecological studies such as biodiversity conservation (Koellner and Schmitz, 2006; Tilman et al., 2006), natural resource management (Halpern et al., 2011) and agriculture (Robison and Brake, 1979; Blank, 1990; Lien and Hardaker, 2001; Di Falco and Perrings, 2005; Rădulescu et al., 2014). Crop diversity can provide farmers with an opportunity to compensate for the loss of revenue caused by the drop of a certain crop price or yield. In view of the variability of price and yield among different crops, crop selection and crop composition in a portfolio is therefore a crucial issue, which has a direct impact on the farm household revenue.

The influences of crop selection and crop portfolio choice on farm household have been studied by several authors. For single crop farming, Klasen et al. (2013), for example, analysed the income dynamics caused by crop choice between coffee and cocoa production.

\footnotetext{
1 "Food security exists when all people, at all times, have physical and economic access to sufficient, safe and nutritious food to meet their dietary needs and food preferences for an active and healthy life" (Rome Declaration on World Food Security and World Food Summit Plan of Action, 1996)
} 
Di Falco and Perrings (2003) studied the effect of crop diversity on mean and variance of income in multiple crop farming. They found that crop diversity increased the mean of income and decreased its variance. Guvele (2001) analysed how multiple crop combinations affect the income variability in Sudan using the mean-variance model. Pellegrini and Tasciotti (2014) revealed the positive effect of crop diversification on income by regression analysis. However, most studies do not pass beyond the mean and variance. Other studies reported the effects of crop diversity on yield, however, the results were not conclusive. Smale et al. (1998), for instance, used a Just-Pope production function (Just and Pope, 1978) to test the relationship between biotic diversity variables and the mean and variance of yield. They found that genealogical variables increased the mean of yield and reduced its variance. Crop diversity also reduced the variance of crop production in Italy (Di Falco and Chavas, 2006) and in Ethiopia (Di Falco et al., 2010) especially when rainfall was low. Di Falco et al. (2010) emphasised that crop diversity was crucial under challenging conditions such as low precipitation. In contrast, Carew et al. (2009), who used the same Just-Pope approach, stated that spatial and temporal diversity had a negative effect on mean yield. Most of the published studies that examined the impact of crop diversity on yield ignored the temporal fluctuations and concentrated on the mean and the variance. To our knowledge, only few studies considered the temporal structure of the data explicitly, except for the use of dummy variables (Smale et al., 1998; Carew et al., 2009). However, the temporal aspect is crucial for the stability of farmers' revenue.

Detecting and quantifying fluctuations over time in data is the domain of time series analysis. It has been applied in various fields of research such as in finance (Liu et al., 1999; Gopikrishnan et al., 2001; Thomakos et al., 2002; Kiyono et al., 2006), meteorology (Allen and Smith, 1994; Talkner and Weber, 2000) and oceanography (Vianna and Menezes, 2006). However, to our knowledge, applications to agro-economic time series are rare in the literature. Singular spectrum analysis is a model-free method to decompose time series into trend, periodicities and noise (Golyandina et al., 2001). Therefore, it allows consideration of different components of a time series. Its data-adaptive character gives it a particular strength compared to classical methods like Fourier analysis and makes it suitable to analyse nonlinear dynamics (Elsner and Tsonis, 1996). Most applications of singular spectrum analysis to economic data focus on forecasting (e.g. Hassani and Thomakos, 2010). In contrast, our goal is the analysis of different components.

Motivated by aforementioned approaches, we aim to quantify the temporal fluctuation of crop price and yield for different choices of crops by using singular spectrum analysis. We apply the crop portfolio theory to farmers' crop selection as a strategy to cope with uncertainties originated from the market (price uncertainty) and from environmental conditions (yield uncertainty). Our goal is to examine the impact of crop selection and composition in portfolios on the farm household revenue. The case study was based on household data collected from the Gangwon Province of South Korea and the nation-wide statistical data. We structured our study into three parts. First, we investigate a farm household survey of farmers' socio-economic background to understand their crop selection decision and to identify empirical crop portfolios based on crops frequently chosen by farmers. This step allows to compare different crop selections in the study region. Second, we use singular spectrum analysis to quantify fluctuations in crop price (1996-2011) and yield data (1980-2011 for most crops, 1965-2011 for rice). In this step, we quantify the fluctuations of each single crop 
and how their trends differ from each other. Third, we finally compare the fluctuations of single crops with those of different empirical crop portfolios constructed in the first step to investigate whether crop diversity might stabilise farm revenue.

\section{Material and methods}

\subsection{Study area}

The study was conducted in the Gangwon Province of South Korea located in the mideastern part of the Korean Peninsula (Supplementary Figure SF1). Eighty-one percent of the total province area is covered with forests and only $10 \%$ is agricultural land. The latter is managed as dry fields (64\%) and rice paddies (36\%) (Gangwon Province, 2016). The annual average temperature is $11.6^{\circ} \mathrm{C}$ (averaged from 1973 to 2009), and the annual average precipitation is $1373 \mathrm{~mm}$. More than half of the annual precipitation falls during the monsoon period, which starts in late June and continues for 30 days on average (Kang et al., 2010).

Because the environmental conditions vary from the coastal areas to the mountain regions, the agricultural practices differ across the province. In the north-western part, for example, rice farming and livestock production such as pigs and chickens dominate. As it is close to Seoul, the capital of South Korea, green house farming is also popular. The regions in the North and South-East are close to the coast and visited by many tourists (Gangwondo Agricultural Research and Extensions Services, 2016). This leads to the development of agritourism, where farmers provide the visitors with an opportunity to experience farming activities (Hong et al., 2003). This can potentially be an income source for farmers. In the south-western part of the province, exporting crop production and off-season fruit farming are the main agricultural activities. In contrast, in the mountainous area with higher altitudes, dry fields (primarily radish and cabbage), fruit production and rice cultivation dominate (Kim et al., 2007).

Due to climate change, the regional distribution of major crops is changing. Apple farming, for example, moved northward from the Gyeongbook Province (in the southern part of South Korea) to the Gangwon Province (Kim et al., 2010). Many farmers try new strategies such as different crop selection to cope with changing farming conditions (Schaefer, 2013). This adjustment might continue with increasing climate change.

\subsection{Farmers' crop selection and empirical crop portfolios}

Face-to-face interviews were conducted between 19th of March 2012 and 6th of April 2012 targeting farmers who produced crops within the watershed of the Soyang Lake in the Gangwon Province of South Korea. Overall, 237 farmers were randomly chosen and interviewed, however, 19 farmers were excluded because of incomplete questions and outliers. The survey data contained farmers' socio-economic characteristics and how many crops were chosen and cultivated per farm household in this region. We used Principal Components Analysis (PCA) to analyse the relationships among these variables and the number of cultivated crops per farm household. PCA is often applied to describe relationships among variables and to identify patterns among them (Castella and Erout, 2002; Lavorel et al., 2011). It reduces the dimension of the data by calculating linear combinations of original variables, the so called

principal components. The principal components are ordered by the amount of variance they 
explain. Thus, the first principal component explains the largest proportion of variance in the data set.

After analysing the socio-economic condition of farmers, we clustered the data by the number of crops chosen per farm household to understand how farmers construct their portfolios of crops. Farmers were categorised into three groups according to the number of crops. The most frequently chosen crops within each group were used to construct empirical crop portfolios. For instance, to determine the crop portfolio for three crops, the major crops chosen by the group of farmers who cultivated three or four crops were considered. Based on these categories, three empirical crop portfolios were constructed.

Subsequently, we compared temporal fluctuations of the crop price and yield between single crops and the empirical portfolios. In order to detect fluctuations of crop price and yield, we analysed nation-wide statistical data (Table ST1 in the online Supplementary Material). The crop price data was provided by the Korea Agro-Fisheries \& Food Trade Corporation (KAMIS) and the Ministry of Food, Agriculture, Forestry and Fisheries. For most of the analysed crops the monthly price data was available from 1996 to 2011. Annual crop yield data of the Gangwon Province (mostly 1980 to 2011) was obtained from the crop production survey by Korean Statistical Information System (KOSIS). The yield data for Ligularia fischeri ${ }^{2}$ was not available.

\subsection{Risk adjusted revenue}

The calculation of risk adjusted revenue is motivated by the Sharpe ratio (Sharpe, 1994), a measure of risk-adjusted performance of mutual funds. We first calculated the nominal revenue by multiplying the annual yield by the annual mean price of crops. Then, the nominal revenue was adjusted by the Consumer Price Index (CPI) to get the real revenue, with 2010 being the reference year. The CPI for living necessaries were obtained from KOSIS. Subsequently, the Sharpe ratio was calculated as

$$
\theta_{p}=\frac{\mu_{p}-R_{f}}{\sigma_{p}},
$$

where $\mu_{p}$ is the average performance of the portfolio (i.e. the mean real revenue, see below), $R_{f}$ is the risk-free rate, and $\sigma_{p}$ is the standard deviation of the portfolio. We used the Sharpe ratio to compare investment options to identify which empirical crop portfolio offered the most risk-efficient investment (Elton et al., 2007). The higher the Sharpe ratio, the lower the investment risk in an empirical crop portfolio.

In this study, we assume that the average performance is only based on the farm revenue which is the income that a farmer gains from only actual farming activities; off-farm income and direct government subsidies were not included. We omitted the risk-free rate because it was the same for all empirical crop portfolios. Under these assumptions, the risk adjusted revenue equals the mean real revenue over the period 1996 to 2011 divided by its standard deviation.

\footnotetext{
${ }^{2}$ Ligularia fischeri is one of the most popular edible wild plants in South Korea, cultivated in mountainous regions like the Gangwon Province. It inhabits mostly central and eastern Asia (Brickell, 2008).
} 


\subsection{Singular Spectrum Analysis}

The Singular Spectrum Analysis (SSA) is a method for time series analysis and forecasting. Since its introduction by Broomhead and King (1986a,b), different SSA methodologies have been developed (e.g. Golyandina and Zhigljavsky, 2013). In this work, we use SSA in its basic form (Basic SSA) or repeatedly (Sequential SSA).

Basic SSA is a non-parametric and model-free technique that decomposes a time series into a set of time series such as trend, (modulated) periodicities and noise. Here, we define trend as any slowly varying time series. Thus, the main goal of SSA decomposition is obtaining components of the original time series that can be interpreted more easily. In this sense, Basic SSA can be regarded as a global data-driven frequency decomposition. The only assumption behind Basic SSA is that the original time series can be represented by a sum of different components (Golyandina and Zhigljavsky, 2013). Therefore, it can be applied to any time series regardless of its stationarity.

We first describe briefly the algorithm of Basic SSA closely following Golyandina and Zhigljavsky (2013) and then explain Sequential SSA. Basic SSA consists of time series decomposition and reconstruction.

Decomposition. Consider a real-valued time series $\mathbb{X}_{N}=\left(x_{1}, \ldots, x_{N}\right)$, where $N$ is the number of data points. First, it is converted into a $L \times K$ trajectory matrix $\mathbf{X}$

$$
\mathbf{X}=\left(\begin{array}{ccccc}
x_{1} & x_{2} & x_{3} & \ldots & x_{K} \\
x_{2} & x_{3} & x_{4} & \ldots & x_{K+1} \\
x_{3} & x_{4} & x_{5} & \ldots & x_{K+2} \\
\vdots & \vdots & \vdots & \ddots & \vdots \\
x_{L} & x_{L+1} & x_{L+2} & \ldots & x_{N}
\end{array}\right)
$$

Its columns consist of lagged vectors of length $L$ of the original time series. In other words, the trajectory matrix is constructed by moving a window of length $L$ through the time series and collecting all $K=N-L+1$ segments.

The second step is the Singular Value Decomposition (SVD) of this trajectory matrix

$$
\mathbf{X}=\mathbf{U} \boldsymbol{\Lambda} \mathbf{V}^{T},
$$

where $\mathbf{U}$ and $\mathbf{V}$ are the left and right singular vectors, respectively, and $\boldsymbol{\Lambda}$ contains $d$ positive singular values $\sqrt{\lambda_{1}} \geq \cdots \geq \sqrt{\lambda_{d}}>0$. Note that the singular values of $\mathbf{X}$ are the square roots of the eigenvalues of the matrix $\mathbf{X X}^{T}$. The collections $\left(\sqrt{\lambda_{i}}, U_{i}, V_{i}\right), i=1, \ldots, d$ of related singular values and singular vectors are called eigentriples.

Reconstruction. To reconstruct components of the time series, we first have to identify which eigentriples should be grouped together. The aim of grouping is to identify the additive components of the time series. We partition the set of indices $\{1, \ldots, d\}$ into $m$ disjoints subsets $I_{1}, \ldots, I_{m}$ and reconstruct the component time series

$$
\mathbf{X}_{I_{p}}=\sum_{i \in I_{p}} \sqrt{\lambda_{i}} U_{i} V_{i}^{T}, \quad p=1, \ldots, m
$$


Thus, we obtain the decomposition of the original trajectory matrix

$$
\mathbf{X}=\mathbf{X}_{I_{1}}+\cdots+\mathbf{X}_{I_{m}}
$$

To recover the additive components of the original time series we have to convert the trajectory matrices back to time series by averaging along the secondary diagonals of the matrices $\mathbf{X}_{I_{p}}$.

The quality of reconstruction is measured by the ratio of eigenvalues. The larger the eigenvalue $\lambda_{i}$, the larger is its ratio $\lambda_{i} / \sum_{i} \lambda_{i}$ and the more important is the component for the reconstruction of the original time series. In order for this ratio to be meaningful, the time series should be normalised by subtracting the mean before the SSA (Golyandina and Zhigljavsky, 2013).

The window length $L$ is a crucial parameter in SSA that strongly influences the decomposition. An inappropriate choice of $L$ might lead to separability issues: The reconstructed components contain a mixture of different periodicities or periodicities and trend. Consequently, the interpretation of such components is difficult. There is no universal rule for choosing $L$, however, some general recommendations exist. Usually, $L \leq N / 2$ is chosen and more details can be extracted for larger $L$. If a dominant periodicity $T$ is present (like the yearly cycle), $L / T$ should be an integer. For small $L, \mathrm{SSA}$ is equivalent to smoothing with a linear filter of width $2 L-1$ (Golyandina and Zhigljavsky, 2013). We chose $L=5$ to decompose the short yield time series.

The longer price time series showed a complex trend and periodicities. For such time series the choice of $L$ might become difficult. Indeed, choosing a large $L$ could mix up periodicities and trend in the same component. On the contrary, for a small $L$ periodic components might be inseparable from each other. To avoid these separability issues we decomposed the price time series by Sequential SSA - a reiteration of Basic SSA. First, the trend is extracted with a small $L_{1}$ and removed from the original time series. Subsequently, the periodicities are extracted from the residual time series with a larger $L_{2}$ (Golyandina and Zhigljavsky, 2013). We chose $L_{1}=12$ and $L_{2}=48$ to extract the trend and the periodicities, respectively.

Our goal is to compare fluctuations between single crops and crop portfolios. It is intuitively clear that with respect to revenue stability, fluctuations with shorter periods are more problematic than those with larger periods. Therefore, we compared the time series on different time scales. For the price data we considered four groups of fluctuations: fluctuations with periods larger than 24 months (trend), periods of 6-24 months (seasonality), 3-5.9 months and smaller than 2.9 months. However, for the yield data we only distinguished between the trend and the remaining periodicities because the time series were short and consisted of yearly measurements. Different periods for rice and the other crops were chosen as the length of the data was different: fluctuations with periods of 23 years and 16 years (trend) for rice and the other crops, respectively. From now on trend and seasonality will take on these temporal meanings. In the reconstruction step (see above) we grouped the eigentriples according to the dominant periodicity that we calculated from the periodogram of the components. A similar approach was used by Mahecha et al. (2010), for example, to compare observations with simulated data in biosphere-atmosphere modelling. The importance of the fluctuations at a certain time scale is shown by the ratio of the eigenvalues. 
We decomposed the price and the yield of single crops and the price of the crop portfolios by SSA. Because the revenue time series contained only 16 values, they were too short for an analysis by SSA. All calculations were done in R (R Core Team, 2013) using the package Rssa (Korobeynikov, 2010; Golyandina and Korobeynikov, 2013).

\section{Results}

\subsection{Farmers' crop selection and empirical crop portfolios}

We classified the 218 farmers into three groups based on the number of cultivated crops. Group 1 included farmers who cultivated one or two crops $(\mathrm{n}=44)$, group 2 those with three or four crops $(\mathrm{n}=100)$, and group 3 summarised farmers cultivating more than five crops $(\mathrm{n}=74)$. These three groups became the basis of the empirical crop portfolios.

The mean age in each group of farmers was 55, 54 and 53 for group 1, group 2 and group 3 , respectively (Table 1). The farming experience increased with the increasing number of crops cultivated. In group 1, the farm size was smaller compared to the other two groups. The farm costs (costs of rent, labour, fertiliser and others) increased with increasing number of crops, which led to lower net income for group 3 with a higher standard deviation. The level of education was available as a categorical variable. The farmers in group 2 had higher education compared to the other two groups. Note that the total number of farmers in each group was different. Among those who had university education, $42 \%$ of farmers cultivated more than five crops.

The results of PCA are summarised in Figure 1 and Table 2. The first two principal components (PC) explained approximately $50 \%$ of the variance (Supplementary Figure SF6). The first component accounted for $31 \%$ of the variance and was positively correlated with education and negatively correlated with farming experience. The second component explained $18.9 \%$ of the variance and was mainly related to the farm size and the number of crops. Subsidy was negatively related to PC 2 and had thus an opposite effect compared to the farm size and the number of crops. In other words, PC 1 distinguished farmers with more education and less farming experience from those with less education and more farming experience as the main source of variability in the socio-economic background of farmers. PC 2 contrasted farmers with large farms growing many crops and having less subsidies to those with smaller farms and less grown crops having larger subsidies. The additional information regarding the farming management type (e.g. organic farming, partially converted farming and conventional farming) is supplied in the Supplementary Figure SF2.

In total 83 types of crops were cultivated in the watershed of the Soyang Lake in the Gangwon Province. However, 93\% of the farmers cultivated one or more crops out of the seven main ones (Table 3). Maize and cabbage shared the same rank. However, because maize is one of the forage crops in South Korea, the market conditions differ from other crops and we excluded it from further analysis. Note that in the survey, farmers recorded all crops they planted. Therefore, the total number of crops and the total number of farmers differ.

The most critical part of building the empirical crop portfolios was to choose the crops and to decide on their relative contribution. In each group of farmers we have selected those who cultivated the smallest number of crops, namely one, three and five. The single crop farming was the basis for the comparison. Subsequently, three- and five-crop portfolios were chosen 


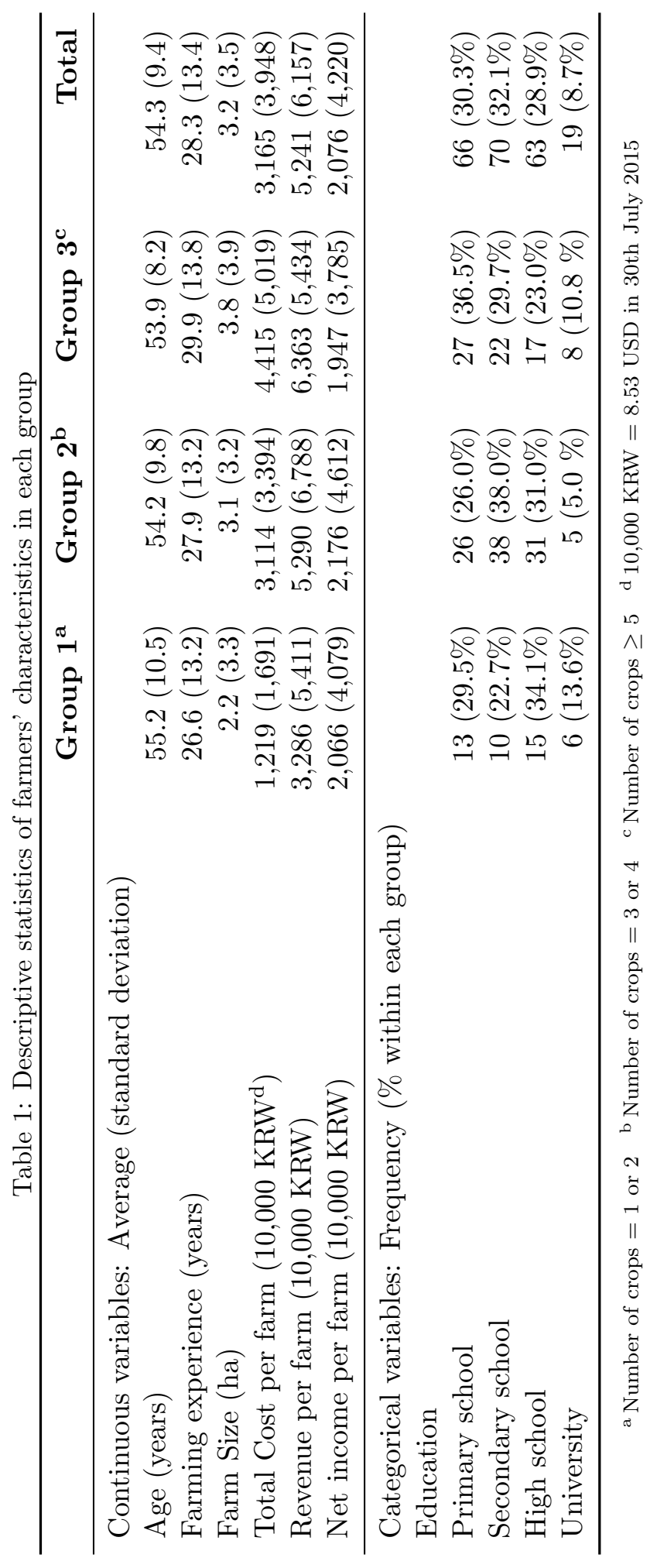




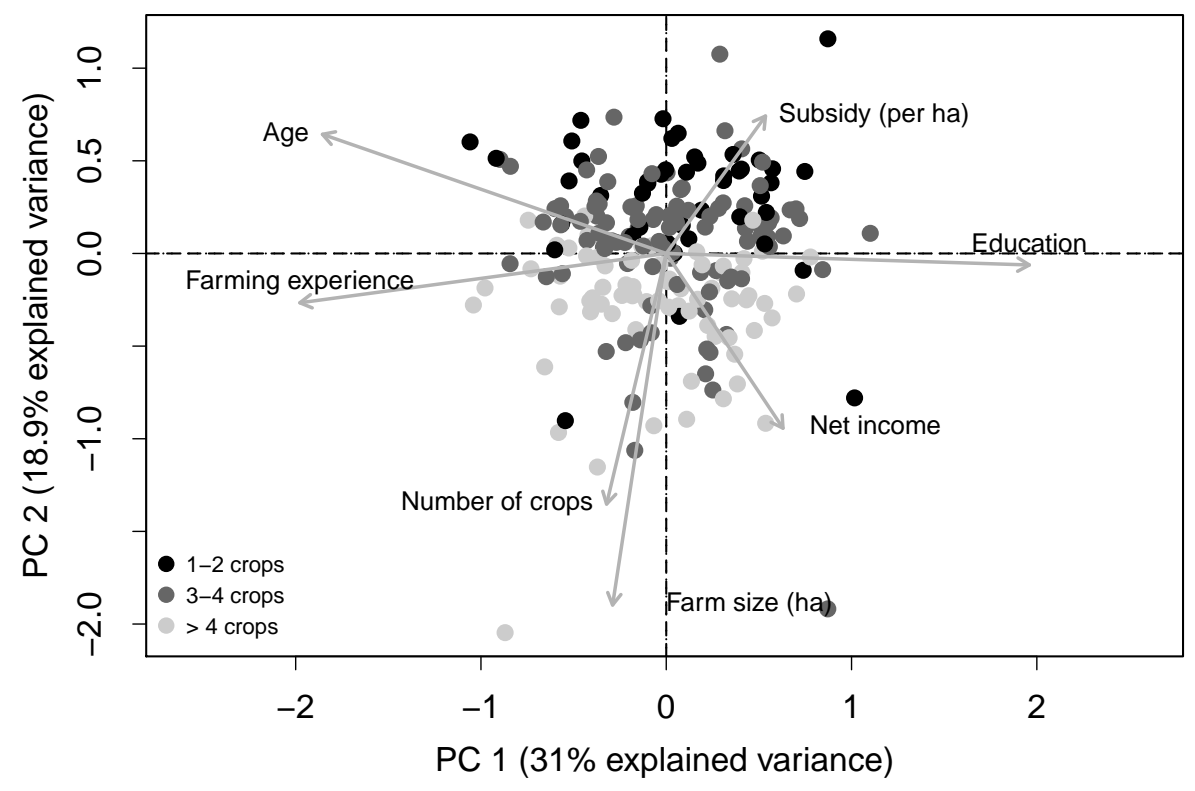

Figure 1: Principal Component Analysis of farmers' characteristics. Arrows show original variables. The direction and the length of the arrows show the correlation between the original variables and the principal components. The more an arrow is parallel to the axis, the more the original variable is related to this particular principal component.

Table 2: Loadings from PCA

\begin{tabular}{lrrrrr}
\hline & PC 1 & PC 2 & PC 3 & PC 4 & PC 5 \\
\hline Education & 0.564 & & & & 0.130 \\
Age & -0.534 & -0.237 & 0.119 & -0.136 & 0.248 \\
Farming experience & -0.569 & & & -0.218 & \\
Farm size (ha) & & 0.700 & & & -0.611 \\
Number of crops & & 0.499 & -0.601 & 0.151 & 0.597 \\
Subsidy (per ha) & 0.154 & -0.273 & -0.653 & -0.636 & -0.249 \\
Net income & 0.181 & 0.348 & 0.445 & -0.708 & 0.356 \\
\hline
\end{tabular}


Table 3: Number of farmers cultivating the eight main crops in the watershed of the Soyang Lake in the Gangwon Province.

\begin{tabular}{rlr}
\hline Rank & Crop & Number of farmers \\
\hline 1 & Pepper & 133 \\
2 & Potato & 116 \\
3 & Beans & 90 \\
4 & Ligularia fischeri & 64 \\
5 & Rice & 59 \\
6 & Radish & 52 \\
7 & Cabbage & 42 \\
7 & Maize & 42 \\
\hline
\end{tabular}

as they were the majorities in each group. Then, we looked at the most selected crops by each group of farmers. Rice was the most frequently cultivated crop by farmers who cultivated a single crop. However, as rice is the main staple grain in South Korea, rice is highly subsidised by the government (Korea Rural Economic Institute, 2015), which might lead to different price conditions compared to the other single crops. Therefore, we decided not to have rice as a representative crop for the single crop farming, but compared all six chosen crops. In the second group, 50 farmers grew three crops, most frequently beans, pepper and cabbage. Finally, in the last group among the 25 farmers with five crops, potato, pepper, beans, cabbage and Ligularia fischeri dominated. However, because Ligularia fischeri was relatively newly introduced to consumers, the price data contained large and regularly occurring gaps (Supplementary Table ST1). Therefore, SSA could not be carried out for this crop. As an alternative, we have included radish in the five-crop portfolio as the sixth most frequently chosen crop by farmers who grew five crops. We calculated the relative proportions of these three or five main crops and composed the empirical crop portfolios as follows:

(1) Single crop farming: six major crops $(100 \%)$

(2) Three-crop portfolio: beans (35.0\%), pepper (32.5\%), and cabbage $(32.5 \%)$

(3) Five-crop portfolio: potato (29.0\%), pepper (27.7\%), beans (17.4\%), cabbage $(14.4 \%)$ and radish $(11.5 \%)$

\subsection{Crop price fluctuations}

\subsubsection{Single crops}

Figure 2 shows the variabilities of crop price fluctuations among six main crops in the Gangwon Province of South Korea. The visual comparison of price data showed that the rice price was extremely stable compared to any other analysed crops during the study period (Figure 2 and Supplementary Figure SF3 for non-normalised price data). Because rice is the most important cereal crop in South Korea (Korea Rural Economic Institute, 2015), several policy instruments such as government buffer stock schemes and direct payments were used to stabilise the rice price (Park et al., 2010). Even though the price for beans was also relatively stable, a sharp increase was registered in 2004. The price for beans in South Korea is highly dependent on foreign trade and is directly influenced by the global market (OECD, 

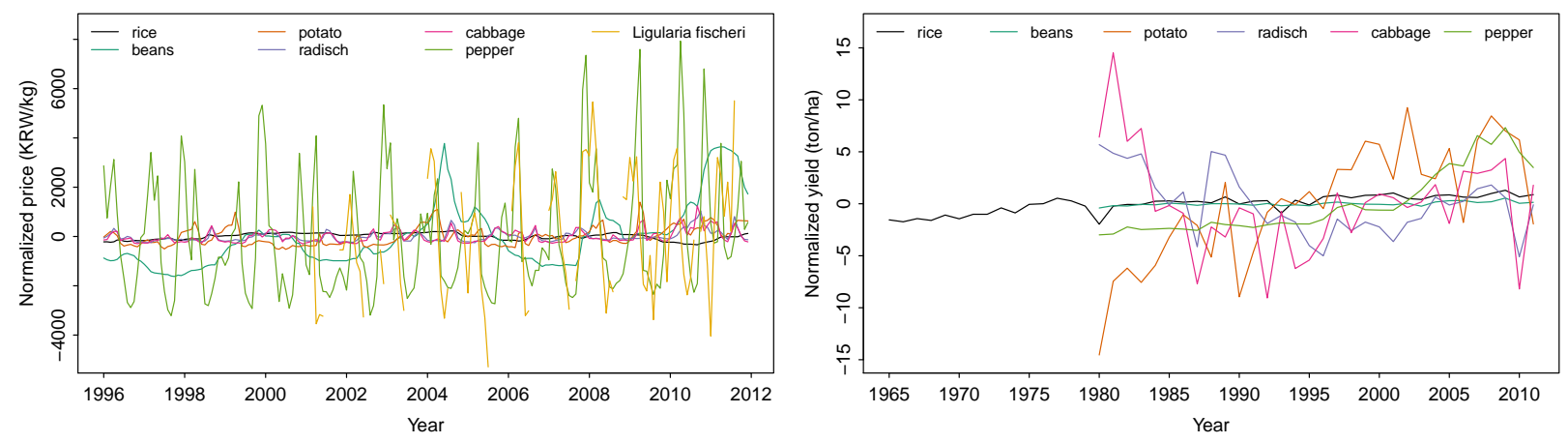

Figure 2: The variability of the normalised crop price (left) and the normalised yield (right) over the analysed period. The respective mean was subtracted from each time series.

2008). Because the U.S. soybean crop yield in 2003 has been the lowest since 1992, the price in 2004 increased dramatically (USDA, 2007). Similarly, a large price rise for cabbage was observed in 2010, although for a different reason (Supplementary Figure SF3 (e) and Figure 2). Due to bad weather in 2010, the supply of cabbage did not meet the demand (Kwon, 2012). In comparison to rice and beans, the prices for pepper and Ligularia fischeri fluctuated strongly.

Figure 3 shows the results of the SSA decomposition of the crop prices. We considered four time scales of fluctuations and evaluated their importance by the ratio of the eigenvalues (c.f. numbers in parenthesis in Figure 3). These numbers show how much each time scale contributes to the reconstruction of the original time series. We associate the periodicities of 24 months and more with a trend and those of 6-24 months with seasonal fluctuations. The third (3-5.9 months) and the fourth $(<2.9$ months $)$ time scales are, however, too short to be interpreted.

The prices for rice and beans showed a large contribution of the trend $(70.1 \%$ and $54.6 \%$, respectively) and a minor one on the smallest time scale (2.6\% and $4 \%$, respectively). This confirms the visual impression of stability in Figure 2. Except for rice, the crop price data showed considerable seasonal patterns with the ratio of eigenvalues exceeding $30 \%$. Radish and pepper exhibited an especially strong seasonal fluctuation, namely $43.6 \%$ and $42.6 \%$, respectively. Compared to rice and beans, cabbage and pepper had a substantial contribution to fluctuations at the smallest time scale (12.4\% and $17.5 \%$, respectively).

\subsubsection{Crop portfolios}

The thee-crop portfolio consisted of beans (35\%), pepper $(32.5 \%)$ and cabbage $(32.5 \%)$ (Figure $4(\mathrm{a})$ ). The SSA of single crops (Figure 3) showed that the bean price was one of the least fluctuating and dominated by the trend, whilst pepper and cabbage exhibited a large seasonal variation. The combination of them increased the contribution of the trend (compared to pepper) and decreased the importance of seasonal fluctuations (compared to pepper and cabbage) (Figure 4 (a)). However, in comparison to the trend-dominated bean price, the fluctuations on all but the largest time scale (trend) increased.

The five-crop portfolio included potato $(29 \%)$, pepper $(27.7 \%)$, beans $(17.4 \%)$, cabbage $(14.4 \%)$ and radish $(11.5 \%)$ (Figure $4(\mathrm{~b})$ ). Compared to the trend-dominated bean price, 

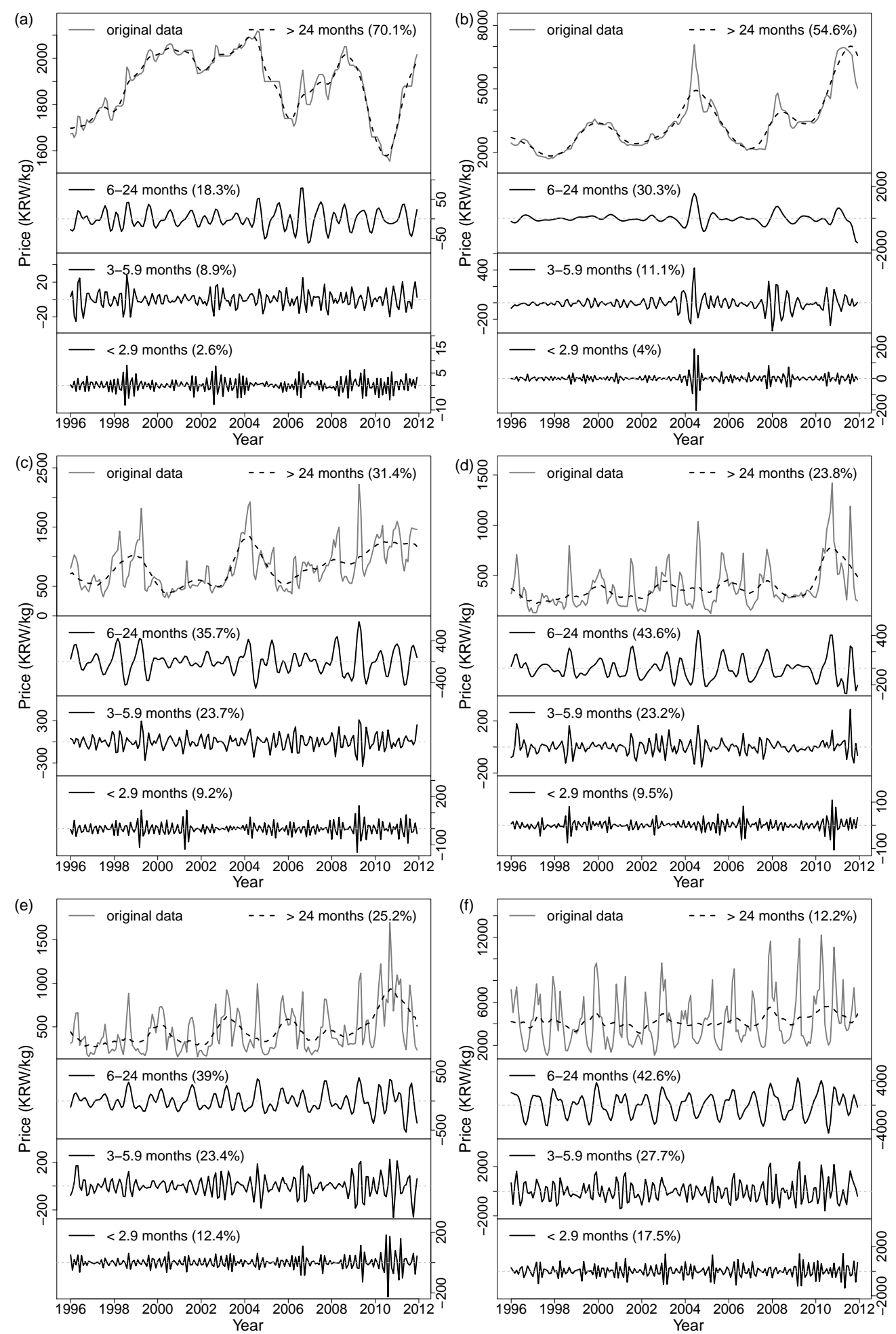

Figure 3: SSA decomposition of the crop prices: (a) rice, (b) beans, (c) potato, (d) radish, (e) cabbage and (f) pepper. Four groups of fluctuation were considered: larger than 24 months (trend), 6-24 months (seasonality), 3-5.9 months, smaller than 2.9 months. The number in parenthesis shows the ratio of eigenvalues. The trend component contains the mean, the others show the variability around it. 

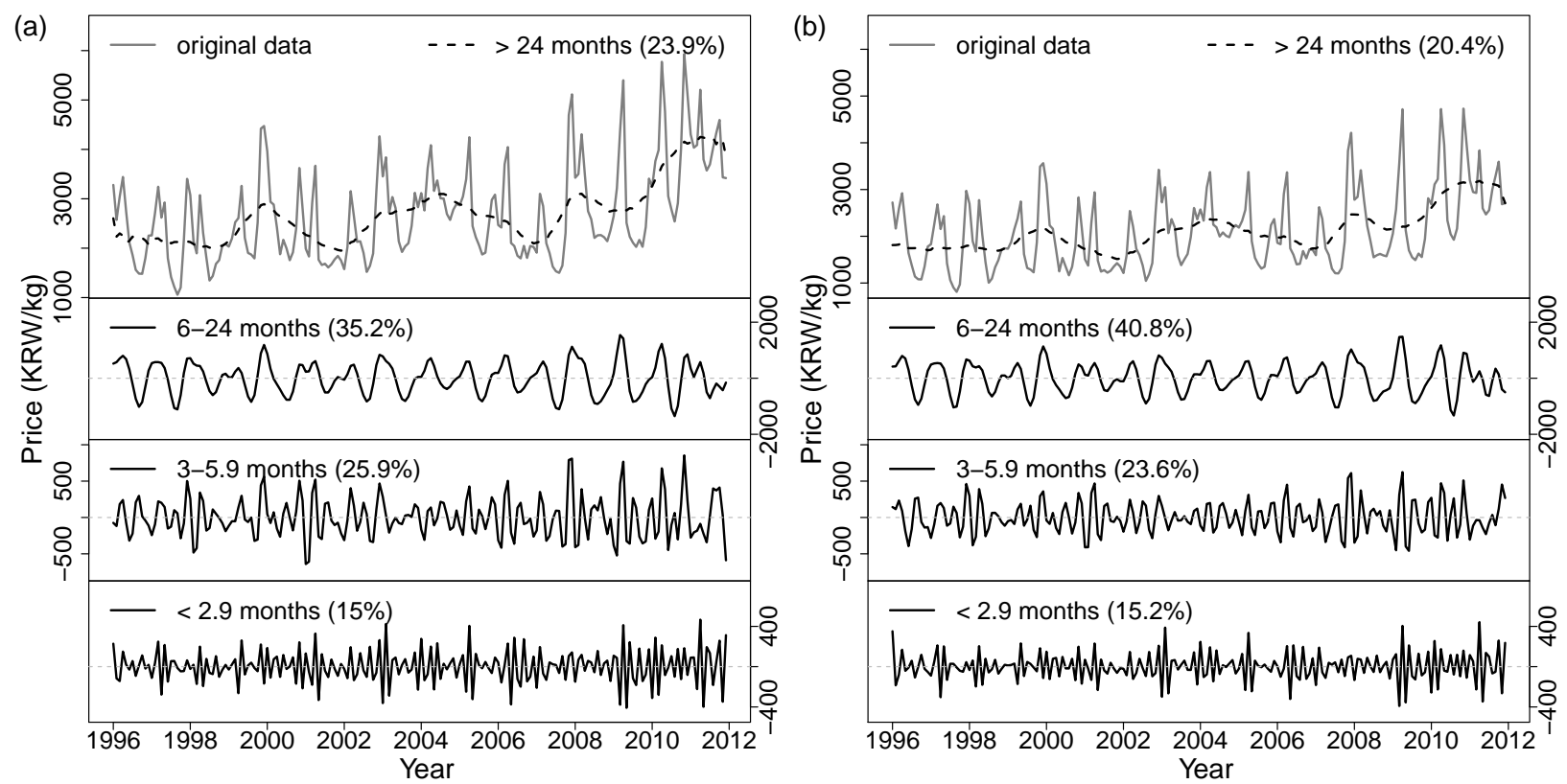

Figure 4: SSA decomposition of the portfolio prices: (a) three-crops portfolio (beans (35.0\%), pepper (32.5\%), and cabbage $(32.5 \%)$ ) and (b) five-crops portfolio (potato $(29 \%)$, pepper $(27.7 \%)$, beans $(17.4 \%)$, cabbage $(14.4 \%)$ and radish (11.5\%)).For both portfolio, four periods of fluctuation were considered: larger than 24 months (trend), 6-24 months (seasonality), 3-5.9 months, smaller than 2.9 months. The number in parenthesis shows the ratio of eigenvalues. The trend component contains the mean, the others show the variability around it.

the contribution of the trend decreased from $54.6 \%$ to $20.4 \%$. Additionally, the contribution of the seasonal fluctuation remained comparable to the other crops that have a strong seasonal pattern. In summary, the results of SSA decomposition were similar to the portfolio composed of three crops. Indeed, the summed contributions of the larger time scales (trend and seasonality) as well as those on the smaller time scales differed only slightly.

\subsection{Crop yield fluctuations}

An in-depth analysis of seasonality was not possible, because the time series of yield consisted of annual measurements. Therefore, we only extracted the trend and calculated the dominant frequency of the remaining periodicities (Figure 5). The result of SSA showed that the contribution of the trend varied from $33.3 \%$ to $66.5 \%$. Accordingly, the importance of periodicities ranged from $33.5 \%$ to $66.7 \%$. Their dominant frequency covered 2.5 years to 10.7 years.

In general, crop yield had an upwards trend during the analysed period, except for radish and cabbage (Figure 5). Four of the six analysed crops, namely rice, beans, potato, and pepper, showed increasing trends in the yields. In contrast, the yield of radish and cabbage had decreased during the 23-year analysed period. There were more negative than positive extreme values outside the range of the standard deviation of the trend. Additionally, the amplitude of negative values was often larger than that of positive values (Figure 5). Interestingly, large negative values occurred in different years for different crops. In 1980 and 1993, for example, the rice yield decreased sharply, whereas there was a relatively high 

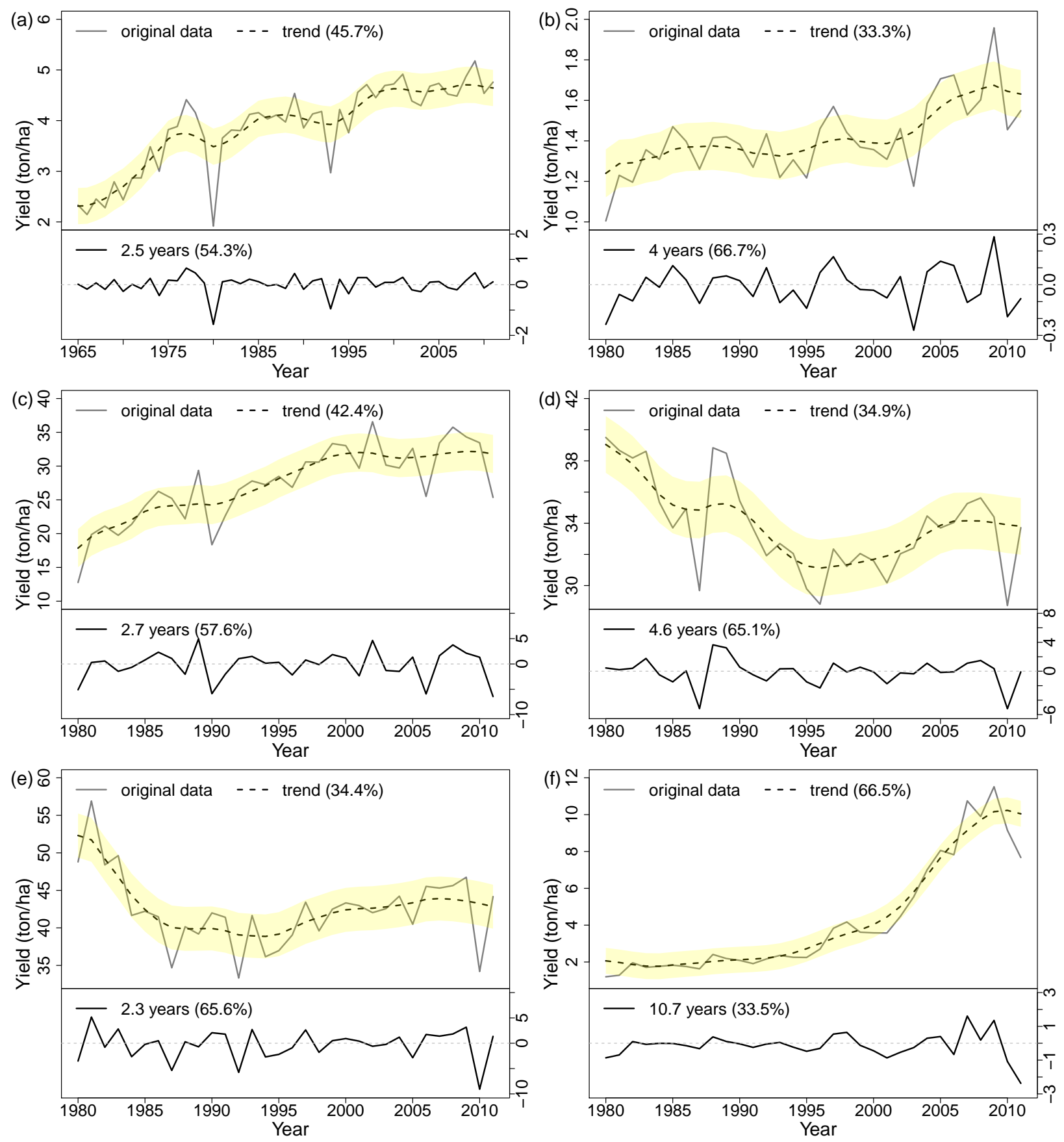

Figure 5: SSA decomposition of the crop yield: (a) rice, (b) beans, (c) potato, (d) radish, (e) cabbage and (f) pepper. The number in parenthesis shows the ratio of eigenvalues. The trend component contains the mean, the others show the variability around it. The yellow area shows \pm standard deviation around the trend component. Note that the time scale is years and not months as for the price data. Fluctuations with periods of 23 years and 16 years (trend) were chosen for rice and the other crops, respectively. 


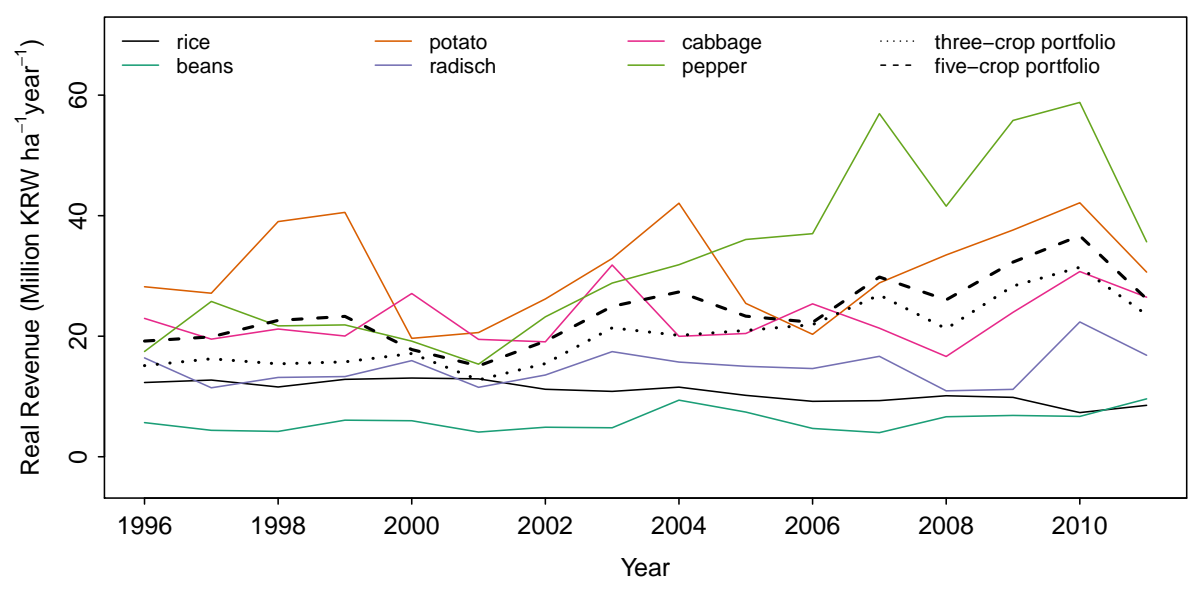

Figure 6: Real revenue for single crops and the empirical crop portfolios.

yield in potato in the same year. In 1996, the radish yield was very low and the rice yield moderately high (See Figure 5 and Supplementary Figure SF4).

The sharp drops of yield often followed damages caused by unusual weather events. Especially in 1980, the rice yield reached only $58.7 \%$ of the target yield of South Korea due to low temperature (Park et al., 2010). In 1987 and 2010, radish and cabbage were also influenced by bad weather (Kwon, 2012). Frequent rain and lack of sunlight during seeding period harmed stabilising seeds (Han and Kim, 2010). In addition, the yield of radish and cabbage has declined as the consumption decreases and imports increase (Korea Rural Economic Institute, 2015). Actually, the import of cabbage has increased since 2003 and westernised eating habits of South Koreans has decreased its consumption by $2 \%$ per year since 2002 (Korea Rural Economic Institute, 2015).

\subsection{Risk adjusted revenue}

The revenue and the Sharpe ratio for each crop portfolio are depicted in Figure 6 and Table 4. The Sharpe ratio is often used to assess the portfolio performance (Blank, 1990; Roche and McQuinn, 2004; Gaydon et al., 2012). For example, Roche and McQuinn (2004) calculated the Sharpe ratio for the farm land allocation portfolio for grains and Gaydon et al. (2012) used it for comparing water management options and their contribution to the farm income.

Figure 6 shows the temporal change of the real revenue of single crops and three-and fivecrop portfolios. Large differences between the six main crops were observed. Rice and beans showed a stable but the smallest and decreasing revenue compared to the other crops over the analysed period. Pepper showed the highest revenue with the highest standard deviation (Table 4). In the portfolio, the mean revenue doubled or tripled and the standard deviation increased with the number of crops compared to rice and bean single crop farming. Although the mean revenue of the crop portfolios was smaller compared to potato and pepper, its standard deviation decreased. The difference between the three- and the five-crop portfolios in mean and standard deviation was only minor. 
Table 4: Risks adjusted revenue for the analysed period from 1996 to 2011.

\begin{tabular}{crrr}
\hline Crop selection & Mean (million KRW) & SD & Sharpe ratio \\
\hline Single crop & & & \\
rice & 10.85 & 1.73 & 6.27 \\
beans & 5.96 & 1.75 & 3.40 \\
potato & 30.92 & 7.70 & 4.01 \\
radish & 14.76 & 2.98 & 4.95 \\
cabbage & 22.88 & 4.35 & 5.26 \\
pepper & 32.94 & 14.20 & 2.32 \\
\hline three-crop portfolio & 20.23 & 5.32 & 3.80 \\
five-crop portfolio & 24.12 & 5.60 & 4.30 \\
\hline
\end{tabular}

\section{Discussion}

An advantage of decomposing the time series is that we can not only identify the most fluctuating crop over time, but also quantify different components of fluctuations in each crop. Fluctuations on larger time scales (trend and seasonality) are easier for farmers to face than short-time variations which are more difficult to address in the planning process. In order to distinguish four time scales of fluctuations in each crop selection we calculated the ratio of eigenvalue for each time scale. The ratio of eigenvalue stands for the quality of the reconstruction of the original time series by a certain component. The larger this ratio, the more important the component will be for the reconstruction. Among four time scales, the first and the second scales can be interpreted as trend and seasonality, respectively; the third and the fourth scales, however, were too short to be identified.

Farmers' decision on which crop to grow, how to allocate the land to grow multiple crops, and when to harvest and sell them plays a crucial role to secure their revenue (Fafchamps, 1992; Kantanantha et al., 2010; Klasen et al., 2013). Our result showed that each crop had a different fluctuation pattern that highly influenced the farm revenue depending on farmers' crop selection. The sum of the first two ratios of eigenvalues for crop price ranged from $54.8 \%$ (pepper) to $88.4 \%$ (rice). The larger the contribution of trend and seasonality, the less shorttime variability is contained in the data. Four of the six analysed crops contained notable seasonal patterns. The SSA of the three- and the five-crop portfolios also revealed that important seasonal variation still remained in the monthly price data. Therefore, seasonality probably has an important impact on farmers' decisions regarding the times for harvesting or marketing of their crops.

The risk adjusted revenue calculated with the Sharpe ratio allows us to compare how much revenue standardised per $1 \%$ of revenue can be guaranteed for farmers in each crop selection. The combination of these methods provides more information to support farmers' decision on crop selection. Although the results of SSA and the Sharpe ratio showed that rice and bean farming were the most stable, they provided the lowest revenue. The revenue of the threeand the five-crop portfolios was more than two times larger than in rice farming, however, at the same time the standard deviation tripled (Table 4). It indicates that the diversified 

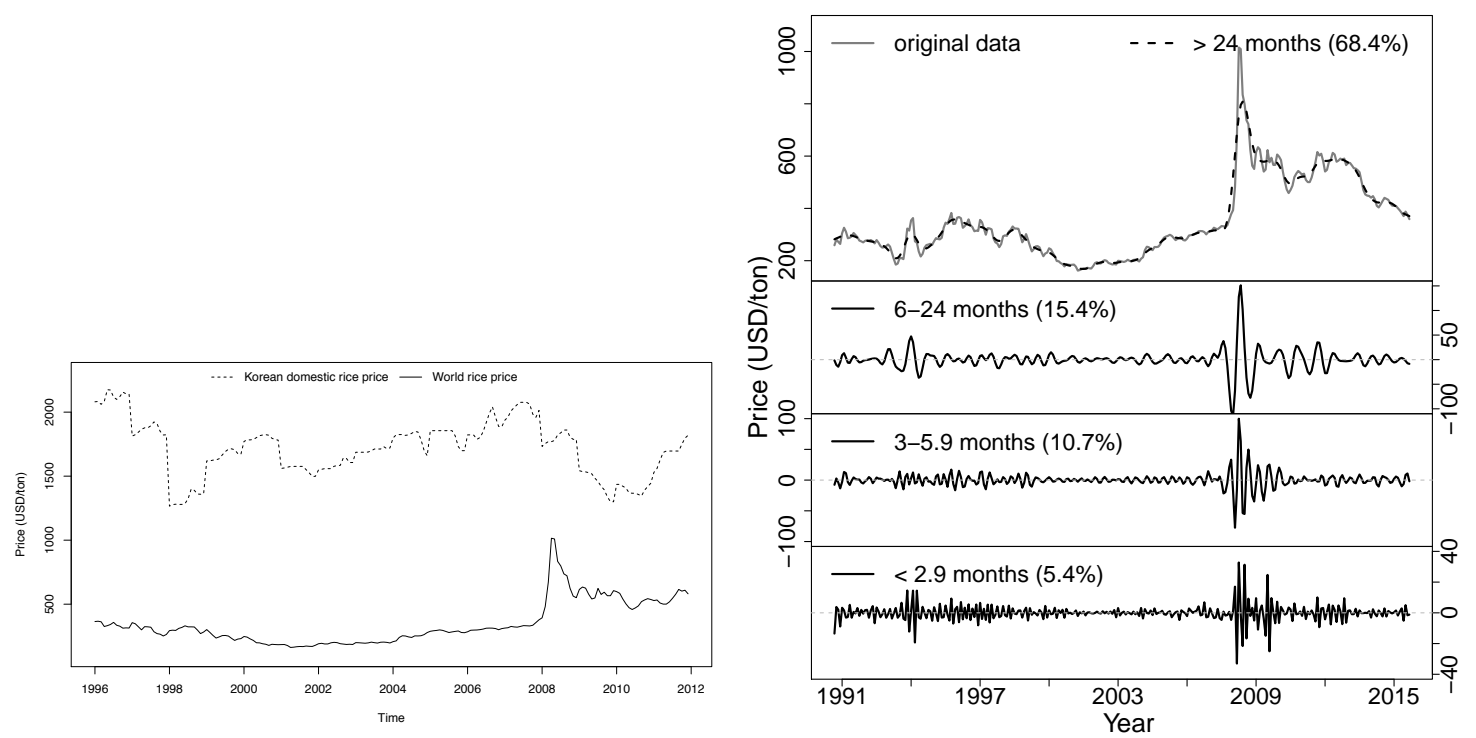

Figure 7: Korean domestic rice price converted in USD/ton and world rice price in USD/ton (left), SSA decomposition of the world rice price (right). Four groups of fluctuation were considered: larger than 24 months (trend), 6-24 months (seasonality), 3-5.9 months, smaller than 2.9 months. The number in parenthesis shows the ratio of eigenvalues. The trend component contains the mean, the others show the variability around it. The world rice data was Thailand nominal price quote obtained from the World Bank Global Economic Monitor (GEM) Commodities. The exchange rate from Korean Won to USD for each year was obtained from the World Bank World Development Indicators.

farming could support larger revenue. This is in accordance with the study by Bhattacharyya (2008) who showed that a rice dominated farming system in India was changed to high-value crops for larger revenue. Furthermore, an analysis in Argentina showed that diversified farming increased the mean return on capital with a lower coefficient of variation (Pacín and Oesterheld, 2014). Hence, the multiple crop farming may be a means of enhancing revenue (Ali et al., 2004; Winters et al., 2006; Pacín and Oesterheld, 2014; Rahman and Kazal, 2015). However, the diversification took place slowly due to agricultural subsidies concentrated on a certain crop such as rice in India (Bhattacharyya, 2008). This might also be the case in South Korea.

To examine the artificial stability of the rice price in South Korea, we compared the domestic rice price with the world rice price in USD (Figure 7). As the exchange rate varies between years, the domestic rice price converted in USD fluctuated more compared to the one in KRW. We refer to the SSA result of the rice price in KRW to keep consistency unless mentioned. While the world rice price increased drastically in 2008 as a result of the oil crisis (Figure 7, right), the Korean domestic price was not affected by it and remained stable (Figure $3(\mathrm{a})$ ). Overall, rice price in the global market fluctuates more than in the South Korean domestic market (Baffes and Cosic, 2013). Furthermore, the Korean domestic price is more than double or triple the world price - the result of a substantial governmental support (Figure 7, left).

South Korea used to have a higher protection for domestic rice farming, mainly through tariff and non-tariff barriers, in comparison to other OECD countries (Aksoy, 2005). Among other conventional crops, Korean subsidy policy focuses particularly on rice farming by sup- 
porting direct payments and government buffer stock schemes (Park et al., 2011). Especially, the direct payment concentrated on rice farming has caused several problems including rice overproduction and shortage of other upland field crops due to a lack of incentives (Park et al., 2011). In addition, our analysis on the socio-economic characteristics of farmers also showed that the subsidy and the number of crops were inversely related both in PC1 and $\mathrm{PC} 2$. This result indicates that farmers who cultivate a small number of crops tend to receive more subsidies and rice was the most frequently chosen crop by farmers who cultivated one crop. The government buffer stock scheme consists of purchases of commodities by the government with the purpose of using commodity storage to stabilise prices in a whole economy as well as in an individual market (Morrow, 1980). These political interventions explain why rice is the most stable crop in South Korea.

However, rice policy has been influenced by external forces and will continue to change. The Uruguay Round Agreement on Agriculture (URAA) was, for instance, a strong force that specified policy rules in 1994 (OECD, 2008). Although rice farming was protected by an import ban until 1995, after the URAA, it was agreed upon that a minimum market for import would be opened and a removal of tariffs would be enacted by 2004 (Seo and Kim, 2005; Wailes, 2005). Therefore, in 2004, additional negotiations such as Doha Development Agenda (DDA) for the rice sector were inevitable. Under the WTO/DDA negotiations for the rice sector in South Korea, Aggregate Measure of Support (AMS) by the government and the tariff were reduced, and the market access has been increased (Park et al., 2010). This can be noticed in the price data (See Supplementary Figure SF3). Actually, the rice price decreased dramatically between 2004 and 2006. Even though the government reformed the rice policy to protect rice farmers under international treaty, the amount of Minimum Market Access (MMA) from other countries to South Korea has been set to continuously increase from 225575 tons in 2005 to 408700 tons in 2014 (OECD, 2008). Since the end of AMS in 2014, Korean government decided to open its rice market and to liberalise it from 2015 on (Ministry of Agriculture, Food and Rural Affairs, 2014). Therefore, the risk of fluctuating revenue for rice farmers will probably increase.

Diversity loss in the agricultural landscape caused by policies has been addressed in various studies (Potter and Burney, 2002; Hollander, 2004; Potter, 2006). Di Falco and Perrings (2005) indicated that both crop diversity and financial support were risk-reducing strategies for farm revenue. Moreover, they stressed that agricultural policy has an influence not only on agricultural intensification as a "side effect", but also on farmers' risk attitude. Our results suggest that the government policy for rice farming has an influence on farmers' decision on crop selection, which decreases the diversity of crop choice.

There is a limitation to our study. Even though the costs of each farming system vary, the cost of management of portfolios was not taken into account for this analysis due to a lack of reliable cost information on national level. The risk adjusted revenue only considered on-farm sales based on price and yield data per year. We followed the assumption from Fafchamps (1992) that the farm revenue of individual crop choice was related to consumption prices. However, farmers declared in the interviews that rice farming was easier and required fewer skills compared to cultivation of other crops. This was also evident from the survey data, which showed higher costs for multi-crop farming than for single crop farming. This difference in portfolio management might be a critical step for farmers to adapt to new crop selections for portfolios. 


\section{Summary and conclusions}

The dynamics of global economics and climate change threaten the stability of the farm household revenue. Farmers, as main actors to promote agricultural policy and secure food production, have taken several actions to minimise risks. Depending on farmers' decision on crop selection, crop diversity can be considered as one of strategies to stabilise their revenue and to minimise the risk under uncertainty by investing in more than one crop through the portfolio theory.

We analysed the crop price and yield fluctuations for six main crops, the three- and the five-crop portfolios by Singular Spectrum Analysis (SSA). The portfolios were constructed based on household survey data. Subsequently, we compared the single-crop farming with the multiple-crop portfolios. Our analysis showed that crop price and yield fluctuations contained different components. The stronger the contribution of larger time scales (namely trend and seasonality) the less short-time variability is contained in the data. Fluctuations on larger time scales (trend and seasonality) are easier for farmers to face than short-time variations that are more difficult to address in the planning process. Our results showed that each crop has a different pattern of price and yield fluctuations. Rice is the most stable crop in South Korea as its variations are mostly composed of trend and seasonality (88.4\%) and the pepper was the most fluctuating crop (54.8\%).

Depending on their crop selection, farmers' revenue can vary. Even though the multiple crop farming with three and five crops did not stabilise farmers' revenue compared to rice and bean farming, it increased stability compared to the other crops. Rice farming differs from cultivating other crops because of external stabilisation by the governmental interference. However, it should be noted that the rice policy has been reformed and a high protection for domestic rice farming would no longer last in the future. Furthermore, growing rice provided the lowest revenue and farmers who cultivate several crops could as much as double their revenue compared to rice farming. Diversified crop farming can therefore be a means of enhancing revenue. These results might have practical consequences for farmers' decisionmaking as well as for agricultural policy.

\section{Acknowledgements}

This study was carried out as part of the International Research Training Group TERRECO (GRK 1565/1) funded by the Deutsche Forschungsgemeinschaft (DFG) at the University of Bayreuth, Germany and the National Research Foundation of Korea (NRF) at Kangwon National University, Chuncheon, South Korea.

\section{References}

Aksoy, M.A., 2005. Global agricultural trade policies, in: Aksoy, M.A., Beghin, J.C. (Eds.), Global Agricultural Trade and Developing Countries. The World Bank, Washington, D.C., pp. 37-53.

Ali, M., Abedullah, Farooq, U., 2004. Diversification with vegetables to improve competitiveness in Asia diversification with vegetables to improve competitiveness in Asia, in: Ali, M. 
(Ed.), Agricultural Diversification and International Competitiveness. Asian Productivity Organization, Tokyo, p. 51-82.

Allen, M.R., Smith, L., 1994. Investigating the origins and significance of low-frequency modes of climate variability. Geophysical Research Letters 21, 883-886.

Awan, M.I., van Oort, P.A., Ahmad, R., Bastiaans, L., Meinke, H., 2015. Farmers' views on the future prospects of aerobic rice culture in pakistan. Land Use Policy 42, 517-526. doi:10.1016/j.landusepol.2014.09.006.

Baffes, J., Cosic, D., 2013. Global economic prospects: Commodity markets outlook. The World Bank, Washington, D.C.

Below, T.B., Mutabazi, K.D., Kirschke, D., Franke, C., Sieber, S., Siebert, R., Tscherning, K., 2012. Can farmers' adaptation to climate change be explained by socio-economic household-level variables? Global Environmental Change 22, 223-235. doi:10.1016/j . gloenvcha. 2011.11.012.

Bhattacharyya, R., 2008. Crop diversification: A search for an alternative income of the farmers in the state of west bengal in India, in: International Conference on Applied Economics - ICOAE 2008.

Blank, S., 1990. Returns to limited crop diversification. Western Journal of Agricultural Economics 15, 204-212.

Bradshaw, B., 2004. Plus c'est la même chose? Questioning crop diversification as a response to agricultural deregulation in Saskatchewan, Canada. Journal of Rural Studies 20, 35-48. doi:10.1016/S0743-0167(03)00033-0.

Bradshaw, B., Dolan, H., Smit, B., 2004. Farm-level adaptation to climatic variability and change: Crop diversification in the Canadian prairies. Climatic Change 67, 119-141.

Brickell, C., 2008. RHS A-Z Encyclopedia Of Garden Plants, Band 1. Dorling Kindersley.

Broomhead, D., King, G.P., 1986a. Extracting qualitative dynamics from experimental data. Physica D: Nonlinear Phenomena 20, 217-236. doi:10.1016/0167-2789 (86)90031-X.

Broomhead, D., King, G.P., 1986b. On the qualitative analysis of experimental dynamical systems, in: Sarkar, S. (Ed.), Nonlinear Phenomena and Chaos. Adam Hilger, Bristol, England, pp. 113-114.

Carew, R., Smith, E.G., Grant, C., 2009. Factors influencing wheat yield and variability: evidence from Manitoba, Canada. Journal of Agricultural and Applied Economics 41, 625-639.

Castella, J.C., Erout, A., 2002. Montane paddy rice: the cornerstone of agricultural production systems in Bac Kan province, Viet Nam, in: Castella, J.C., Quang, D.D. (Eds.), Doi Moi in the Mountains. Land use changes and farmers' livelihood strategies in Bac Kan Province, Vietnam. The Agricultural Publishing House, Ha Noi, Viet Nam, pp. 175-195. 
Cutforth, L.B., Francis, C.A., Lynne, G.D., Mortensen, D.A., Eskridge, K.M., 2001. Factors affecting farmers' crop diversity decisions: An integrated approach. American Journal of Alternative Agriculture 16, 168-176. doi:10.1017/S0889189300009164.

Di Falco, S., Bezabih, M., Yesuf, M., 2010. Seeds for livelihood: Crop biodiversity and food production in Ethiopia. Ecological Economics 69, 1695-1702. doi:10.1016/j .ecolecon . 2010.03 .024$.

Di Falco, S., Chavas, J.P., 2006. Crop genetic diversity, farm productivity and the management of environmental risk in rainfed agriculture. European Review of Agricultural Economics 33, 289-314. doi:10.1093/eurrag/jbl016.

Di Falco, S., Perrings, C., 2003. Crop genetic diversity, productivity and stability of agroecosystems. a theoretical and empirical investigation. Scottish journal of political economy 50, 207-216. doi:10.1111/1467-9485.5002006.

Di Falco, S., Perrings, C., 2005. Crop biodiversity, risk management and the implications of agricultural assistance. Ecological Economics 55, 459-466. doi:10.1016/j.ecolecon. 2004.12 .005$.

van Dusen, M.E., Taylor, J.E., 2005. Missing markets and crop diversity: evidence from mexico. Environment and Development Economics 10, 513-531. doi:10.1017/ S1355770X05002317.

Elsner, J.B., Tsonis, A.A., 1996. Singular spectrum analysis: A new tool in time series analysis. Plenum Press, New York.

Elton, E., Gruber, M., Brown, S., Goetzmann, W., 2007. Modern portfolio theory and investment analysis. 7 ed., Wiley, New York.

Fader, M., Gerten, D., Krause, M., Lucht, W., Cramer, W., 2013. Spatial decoupling of agricultural production and consumption: quantifying dependences of countries on food imports due to domestic land and water constraints. Environmental Research Letters 8, 014046. doi:10.1088/1748-9326/8/1/014046.

Fafchamps, M., 1992. Cash crop production, food price volatility, and rural market integration in the third world. American Journal of Agricultural Economics 74, 90-99. URL: http: //www. jstor .org/stable/1242993.

FAO, IFAD, IMF, OECD, UNCTAD, WFP, the World Bank, the WTO, IFPRI, the UN HLTF, 2011. Price Volatility in Food and Agricultural Markets: Policy Responses. Technical Report. FAO and OECD.

Feola, G., Lerner, A.M., Jain, M., Montefrio, M.J.F., Nicholas, K.A., 2015. Researching farmer behaviour in climate change adaptation and sustainable agriculture: Lessons learned from five case studies. Journal of Rural Studies 39, 74-84.

Gangwon-do Agricultural Research and Extensions Services, 2016. http://www.ares . gangwon.kr/hb/en/sub01_04. Accessed in June 2016. 
Gangwon Province, 2016. http://www.provin.gangwon.kr/gw/portal/sub03_01. In Korean, Accessed in June 2016.

Gaydon, D., Meinke, H., Rodriguez, D., McGrath, D., 2012. Comparing water options for irrigation farmers using modern portfolio theory. Agricultural Water Management 115, 1-9. doi:10.1016/j. agwat. 2012.08.007.

Golyandina, N., Korobeynikov, A., 2013. Basic singular spectrum analysis and forecasting with r. Computational Statistics \& Data Analysis 71, 934-954. doi:10.1016/j.csda. 2013.04.009.

Golyandina, N., Nekrutkin, V., Zhigljavsky, A.A., 2001. Analysis of time series structure: SSA and related techniques. Chapman \& Hall/CRC, Boca Raton, Fla.

Golyandina, N., Zhigljavsky, A., 2013. Singular spectrum analysis for time series. Springer.

Gopikrishnan, P., Rosenow, B., Plerou, V., Stanley, H., 2001. Quantifying and interpreting collective behavior in financial markets. Physical Review E 64, 035106. doi:10.1103/ PhysRevE.64.035106.

Guvele, C., 2001. Gains from crop diversification in the sudan gezira scheme. Agricultural Systems 70, 319-333.

Halpern, B.S., White, C., Lester, S.E., Costello, C., Gaines, S.D., 2011. Using portfolio theory to assess tradeoffs between return from natural capital and social equity across space. Biological Conservation 144, 1499-1507. doi:10.1016/j.biocon.2011.01.019.

Han, G., Kim, T., 2010. Causes of recent cabbage shock and policy implications (in Korean). volume 255 of $C E O$ focus. Nonghyup Economic Research Institute. 15.

Harvey, C.A., Rakotobe, Z.L., Rao, N.S., Dave, R., Razafimahatratra, H., Rabarijohn, R.H., Rajaofara, H., MacKinnon, J.L., 2014. Extreme vulnerability of smallholder farmers to agricultural risks and climate change in madagascar. Philosophical Transactions B of the Royal Society 369, 20130089. doi:10.1098/rstb.2013.0089.

Hassani, H., Thomakos, D., 2010. A review on singular spectrum analysis for economic and financial time series. Statistics and its Interface 3, 377-397.

Heady, E.O., 1952. Diversification in resource allocation and minimization of income variability. Journal of Farm Economics 34, 482-496.

Herrero, M., Thornton, P.K., Bernués, A., Baltenweck, I., Vervoort, J., van de Steeg, J., Makokha, S., van Wijk, M.T., Karanja, S., Rufino, M.C., Staal, S.J., 2014. Exploring future changes in smallholder farming systems by linking socio-economic scenarios with regional and household models. Global Environmental Change 24, 165-182. doi:10.1016/ j.gloenvcha.2013.12.008.

Hollander, G.M., 2004. Agricultural trade liberalization, multifunctionality, and sugar in the south Florida landscape: Themed issue on 'neoliberal nature and the nature of neoliberalism'. Geoforum 35, 299-312. doi:10.1016/j .geoforum.2003.11.004. 
Hong, S., Kim, S., Kim, J., 2003. Implications of potential green tourism development. Annals of Tourism Research 30, 323-341. doi:10.1016/S0160-7383(02)00060-9.

Ilbery, B.W., 1978. Agricultural decision-making: a behavioural perspective. Progress in Human Geography 2, 448-466.

Janssen, S., van Ittersum, M.K., 2007. Assessing farm innovations and responses to policies: A review of bio-economic farm models. Agricultural Systems 94, 622-636. doi:10.1016/ j.agsy. 2007.03 .001$.

Just, R.E., Pope, R.D., 1978. Stochastic specification of production functions and economic implications. Journal of Econometrics 7, 67-86. doi:10.1016/0304-4076 (78)90006-4.

Kang, M., Kang, S., Ryu, C., 2010. A study on climate change in gangwon-province (in Korean). Proceedings of the Korean Environmental Sciences Society Conference 19, 139141.

Kantanantha, N., Serban, N., Griffin, P., 2010. Yield and price forecasting for stochastic crop decision planning. Journal of Agricultural, Biological, and Environmental Statistics 15, 362-380. doi:10.1007/s13253-010-0025-7.

Kim, C., Lee, S., Jeong, H., Jang, J., Kim, Y., Lee, C., 2010. Impacts of Climate Change on Korean Agriculture and Its Counterstrategies. Research Report, R593. Korea Rural Economic Institute, Seoul.

Kim, S., Yang, J., Park, C., Jung, Y., Cho, B., 2007. Effects of winter cover crop of ryegrass (lolium multiflorum) and soil conservation practices on soil erosion and quality in the sloping uplands. Journal of Applied Biological Chemistry 50, 22-28.

Kiyono, K., Struzik, Z., Yamamoto, Y., 2006. Criticality and phase transition in stock-price fluctuations. Physical Review Letters 96,068701. doi:10.1103/PhysRevLett.96.068701.

Klasen, S., Priebe, J., Rudolf, R., 2013. Cash crop choice and income dynamics in rural areas: evidence for post-crisis indonesia. Agricultural Economics 44, 349-364. doi:10. 1111 /agec. 12015.

Koellner, T., Schmitz, O.J., 2006. Biodiversity, ecosystem function, and investment risk. BioScience 56, 977-985. doi:10.1641/0006-3568(2006)56 [977:BEFAIR] 2.0 . C0;2.

Korea Rural Economic Institute, 2015. Agriculture in Korea. Korea Rural Economic Institute.

Korobeynikov, A., 2010. Computation- and space-efficient implementation of SSA. Statistics and Its Interface 3, 357-368. R package version 0.9.9.

Kristensen, S.P., Thenail, C., Kristensen, L., 2001. Farmers' involvement in landscape activities: An analysis of the relationship between farm location, farm characteristics and landscape changes in two study areas in jutland, denmark. Journal of Environmental Management 61, 301-318. doi:10.1006/jema.2000.0409. 
Kwon, W., 2012. Climate change scenario and applications in agriculture (in Korean), in: Korea Rural Economic Institute (Ed.), Agricultural Outlook. Korea Rural Economic Institute, Seoul. E04-2012, pp. 997-1026.

Lavorel, S., Grigulis, K., Lamarque, P., Colace, M.P., Garden, D., Girel, J., Pellet, G., Douzet, R., 2011. Using plant functional traits to understand the landscape distribution of multiple ecosystem services. Journal of Ecology 99(1), 135-147. doi:10.1111/j . 1365-2745.2010.01753.x.

Lien, G., Hardaker, J., 2001. Whole-farm planning under uncertainty: impacts of subsidy scheme and utility function on portfolio choice in Norwegian agriculture. European Review of Agricultural Economics 28, 17-36. doi:10.1093/erae/28.1.17.

Liu, Y., Gopikrishnan, P., Cizeau, P., Meyer, M., Peng, C.K., Stanley, H.E., 1999. Statistical properties of the volatility of price fluctuations. Physical Review E 60, 1390-1400. doi:10. 1103/PhysRevE.60.1390.

Mahecha, M.D., Reichstein, M., Jung, M., Seneviratne, S.I., Zaehle, S., Beer, C., Braakhekke, M.C., Carvalhais, N., Lange, H., Le Maire, G., Moors, E., 2010. Comparing observations and process-based simulations of biosphere-atmosphere exchanges on multiple timescales. Journal of Geophysical Research 115, G02003. doi:10.1029/2009JG001016.

Markowitz, H., 1952. Portfolio selection. The Journal of Finance 7, 77-91. doi:10.1111/j . 1540-6261.1952.tb01525.x.

Ministry of Agriculture, Food and Rural Affairs, 2014. http://www.mafra.go.kr/rice/ 01/01_03.html. In Korean, Accessed in June 2016.

Mishra, A.K., El-Osta, H.S., Morehart, M.J., Johnson, J.D., Hopkins, J.W., 2002. Income, Wealth, and the Economic Well-Being of Farm Households. Agricultural Economic Report 812. U.S. Department of Agriculture, Washington, DC. 1800 M Street, NW, Washington, DC 20036-5831.

Morrow, Daniel, T., 1980. The economics of the international Stockholding of wheat. International Food Policy Research Institute.

OECD, 2008. Evaluation of Agricultural Policy Reforms in Korea. Technical Report. OECD, Paris.

Olesen, J., Trnka, M., Kersebaum, K., Skjelvåg, A., Seguin, B., Peltonen-Sainio, P., Rossi, F., Kozyra, J., Micale, F., 2011. Impacts and adaptation of European crop production systems to climate change. European Journal of Agronomy 34, 96-112. doi:10.1016/j . eja.2010.11.003.

Pacín, F., Oesterheld, M., 2014. In-farm diversity stabilizes return on capital in argentine agro-ecosystems. Agricultural Systems 124, 51-59. doi:10.1016/j .agsy.2013.10.008. 
Park, D., Kim, M., Park, M., Sa, G., Kim, G., 2010. Debate for the development of the rice industry (in Korean). Number D287 in Research Report, Korea Rural Economic Institute, Seoul.

Park, S., Park, J., Song, J., Chae, G., Moon, H., 2011. Research on agricultural subsidy refrom (in Korean). P140, Korea Rural Economic Institute.

Pellegrini, L., Tasciotti, L., 2014. Crop diversification, dietary diversity and agricultural income: empirical evidence from eight developing countries. Canadian Journal of Development Studies/Revue canadienne d'études du développement , 211-227doi:10.1080/ 02255189.2014 .898580$.

Potter, C., 2006. Competing narratives for the future of European agriculture: The agrienvironmental consequences of neoliberalization in the context of the Doha round. The Geographical Journal 172, 190-196. URL: http://www jstor .org/stable/3873962.

Potter, C., Burney, J., 2002. Agricultural multifunctionality in the WTO-legitimate nontrade concern or disguised protectionism? Journal of Rural Studies 18, 35-47. doi:10. 1016/S0743-0167(01)00031-6.

Potter, C., Lobley, M., 1992. The conservation status and potential of elderly farmers: Results from a survey in england and wales. Journal of Rural Studies 8, 133-143. doi:10 . 1016/0743-0167(92)90072-E.

R Core Team, 2013. R: A Language and Environment for Statistical Computing. R Foundation for Statistical Computing. Vienna, Austria. URL: http://www.R-project.org/.

Rădulescu, M., Rădulescu, C.Z., Zbăganu, G., 2014. A portfolio theory approach to crop planning under environmental constraints. Annlas of Operations Research 219, 243-264. doi:10.1007/s10479-011-0902-7.

Rahman, S., 2009. Whether crop diversification is a desired strategy for agricultural growth in Bangladesh? Food Policy 34, 340-349.

Rahman, S., Kazal, M.M.H., 2015. Determinants of crop diversity in the regions of bangladesh (1990-2008). Singapore Journal of Tropical Geography 36, 83-97.

Robison, L.J., Brake, J.R., 1979. Application of portfolio theory to farmer and lender behavior. American Journal of Agricultural Economics 61. URL: http://www.jstor . org/stable/1239520.

Roche, M.J., McQuinn, K., 2004. Riskier product portfolio under decoupled payments. European Review of Agricultural Economics 31, 111-123.

Rome Declaration on World Food Security and World Food Summit Plan of Action, 1996. URL: http: //www.fao .org/DOCREP/003/W3613E/W3613E00. HTM.

Schaefer, S., 2013. The South Korean adaptation actor-network in the agricultural sector. Ph.D. thesis. University of Bayreuth. 
Seo, J., Kim, B., 2005. Forecast and challenges of Korea rice farming after the rice negotiation (in Korean), in: Oh, S.I. (Ed.), Agriculture Forecast (I). Korea Rural Economic Institute, pp. $57-79$.

Sharpe, W.F., 1994. The sharpe ratio. The Journal of Portfolio Management 21, 49-58. doi:10.3905/jpm.1994.409501.

Smale, M., Hartell, J., Heisey, P.W., Senauer, B., 1998. The contribution of genetic resources and diversity to wheat production in the Punjab of Pakistan. American Journal of Agricultural Economics 80, 482-493. URL: http://www.jstor .org/stable/1244551.

Talkner, P., Weber, R.O., 2000. Power spectrum and detrended fluctuation analysis: Application to daily temperatures. Physical Review E 62, 150-160. doi:10.1103/PhysRevE. 62.150.

Thomakos, D.D., Wang, T., Wille, L.T., 2002. Modeling daily realized futures volatility with singular spectrum analysis. Physica A: Statistical Mechanics and its Applications 312, 505-519. doi:10.1016/S0378-4371(02)00845-2.

Tilman, D., Reich, P.B., Knops, J.M.H., 2006. Biodiversity and ecosystem stability in a decade-long grassland experiment. Nature 441, 629-632. doi:10.1038/nature04742.

USDA, 2007. Soybean Objective Yield Survey Data, 1992-2006. Technical Report. the National Agricultural Statistics Service (NASS), Agricultural Statistics Board, U.S. Department of Agriculture.

Vianna, M.L., Menezes, V.V., 2006. Singular spectrum analysis of nonstationary tidal currents applied to ADCP data from the Northeast Brazilian shelf. Journal of Atmospheric and Oceanic Technology 23, 138-151. doi:10.1175/JTECH1824.1.

Wailes, E.J., 2005. Rice: Global trade, protectionist policies, and the impact of trade libralization, in: Aksoy, M.A., Beghin, J. (Eds.), Global Agricultural Trade and Developing Countries. The World Bank, Washington, D.C., pp. 177-193.

Wang, J., Mendelsohn, R., Dinar, A., Huang, J., 2010. How Chinese farmers change crop choice to adapt to climate change. Climate Change Economics 1, 167-185. doi:10.1142/ S2010007810000145.

Winters, P., Cavatassi, R., Lipper, L., 2006. Sowing the Seeds of Social Relations: The Role of Social Capital in Crop Diversity. ESA Working Paper 06-16. The Food and Agriculture Organization of the United Nations. Rome, Italy.

Wood, S.A., Jina, A.S., Jain, M., Kristjanson, P., DeFries, R.S., 2014. Smallholder farmer cropping decisions related to climate variability across multiple regions. Global Environmental Change 25, 163-172. doi:10.1016/j.gloenvcha.2013.12.011. 